\title{
O refino de petróleo no Paraná: Uma análise geoeconômica
}

Le raffinage du petroleum à Paraná: une analyse geoeconomique

El refino de petróleo en Paraná: un análisis geoeconómica

The refining of petroleum in Paraná: a geoeconomic analysis

\section{Pierre Costa and Lisandro Pezzi Schmidt}

\section{(2) OpenEdition}

\section{Journals}

Electronic version

URL: http://journals.openedition.org/espacoeconomia/6058

DOI: 10.4000/espacoeconomia.6058

ISSN: 2317-7837

\section{Publisher}

Núcleo de Pesquisa Espaço \& Economia

\section{Electronic reference}

Pierre Costa and Lisandro Pezzi Schmidt, « O refino de petróleo no Paraná: Uma análise geoeconômica », Espaço e Economia [Online], 14 | 2019, Online since 12 August 2019, connection on 04 September 2019. URL : http://journals.openedition.org/espacoeconomia/6058 ; DOI : 10.4000/ espacoeconomia.6058

This text was automatically generated on 4 September 2019.

(C) NUPEE 


\title{
O refino de petróleo no Paraná: Uma análise geoeconômica
}

\author{
Le raffinage du petroleum à Paraná: une analyse geoeconomique \\ El refino de petróleo en Paraná: un análisis geoeconómica \\ The refining of petroleum in Paraná: a geoeconomic analysis
}

Pierre Costa and Lisandro Pezzi Schmidt

\section{Introdução}

1 Segundo Egler e Mattos (2012), o petróleo é a indústria símbolo do século XX, um período definido pelo desenvolvimento das tecnologias de comunicação, pela mundialização do capital, pela constituição das redes produtivas e pela abertura de mercados, até mesmo de trabalho. A distância em relação aos mercados consumidores e a dispersão geográfica das jazidas são atributos da indústria petrolífera, e delinearam não somente o progresso tecnológico, como também a formação de uma estrutura institucional propícia a essa conjuntura. Portanto, sendo importante a constituição e proliferação de empresas multinacionais que ofereçam investimentos diretos em outros países e transfiram e aumentem os interesses dos Estados. Estes passam a se localizar em escalas superpostas, extrapolando seus limites e embrenhando territórios de outras nações (VELTZ, 2004).

Em relação ao Brasil, mais especificamente sobre a Petrobras, da qual pertence a Refinaria Presidente Getúlio Vargas (REPAR), é interessante reproduzirmos a posição de Contreras (1994, p. 15):

A trajetória da Petrobrás é relevante, sobretudo pela sua qualidade: verticalmente integrada, conglomerada e internacionalizada. 0 elevado potencial de acumulação de sua atividade-eixo obviamente promoveu sua dinâmica microeconômica típica de grande firma. Entretanto, esta dinâmica, que rompe os limites originais de competência, foi muito catalisada pelo animus privado, schumpeteriano e internacionalizante do projeto de suas elites, que transformaram o grupo estatal numa organização solidária com os interesses do capital privado nacional. 
A respeito de Araucária, onde está sitiada a REPAR, ressaltamos que a partir do início da construção da refinaria (1973), o município vivenciou profundas transformações sociaiseconômicas-territoriais. Dentre elas, destacamos: intensos processos de urbanização e industrialização, mudança da base econômica calcada na produção de erva-mate para se tornar um município da indústria e do trabalho fabril; agravamento dos problemas sociais e ambientais.

4 Iniciamos o artigo apresentando as considerações sobre a atividade de refino no Brasil. Em seguida, analisamos a Petrobras Transporte S.A. (Transpetro), pertencente a Holding Petrobras. Num terceiro momento, tratamos sobre as relações socioespaciais entre a REPAR e o município de Araucária. Posteriormente, versamos a respeito dos terminais aquaviários da Petrobras que atendem a REPAR. E, por último, expomos as considerações finais.

\section{0 refino do petróleo no Brasil ${ }^{2}$}

6 Em 2017, o parque de refino brasileiro contava com 17 refinarias, com capacidade para processar aproximadamente 2,4 milhões de barris/dia, valor 1,9\% maior que em 2014. A capacidade de refino medida em barris/dia-calendário foi de 2,3 milhões de barris/dia. 0 fator de utilização das refinarias no ano foi de $76,2 \%$. Treze dessas refinarias pertencem à Petrobras e respondem por $98,2 \%$ da capacidade total, sendo a Replan (SP) a de maior capacidade instalada: 434 mil barris/dia ou $18,0 \%$ do total nacional (vide quadro $1 \mathrm{e}$ mapa 1). Manguinhos (RJ), Riograndense (RS), Univen (SP) e Dax Oil (BA) são refinarias privadas. (ANP, 2018).

Em 2017, foi processada uma carga de 1,7 milhão de barris/dia pelo parque de refino nacional, total dividido entre 1,7 milhão de barris/dia de petróleo $(96,1 \%$ da carga total) e 68,6 mil barris/dia de outras cargas (resíduos de petróleo, resíduos de terminais e resíduos de derivados). Houve um decréscimo de $91,6 \mathrm{mil}$ barris/dia $(5,2 \%)$ no volume de petróleo processado em relação a 2016, dos quais menos 63,7 mil barris/dia de petróleo nacional e menos 27,9 mil barris/dia de petróleo importado. Do petróleo total processado, $91,9 \%$ eram de origem nacional e $8,1 \%$ importada. (ANP, 2018, p. 98). 
Quadro 1. Dados gerais sobre as refinarias de petróleo brasileiras - 2018.

Image

10246C880000743300006151E757DC2D65F8D690.emf

\begin{tabular}{|c|c|c|c|c|c|}
\hline Nome das Refinarias & Sigla & $\begin{array}{l}\text { Localização } \\
\text { (municipio/estado/região) }\end{array}$ & $\begin{array}{l}\text { Capacida- } \\
\text { de refino } \\
(\mathrm{bbl} / \mathrm{d})^{1}\end{array}$ & \begin{tabular}{|l|} 
Ano da \\
implantação
\end{tabular} & $\begin{array}{l}\text { Tipo de } \\
\text { economia }\end{array}$ \\
\hline 1. Riograndense & & Rio Grande/RS/S & 17.014 & 1937 & Privada \\
\hline $\begin{array}{l}\text { 2. Landulfo Alves } \\
\text { (Mataripe) }\end{array}$ & RLAM & $\begin{array}{l}\text { São Francisco do } \\
\text { Conde/BA/NE }\end{array}$ & 377.389 & 1950 & Petrobras \\
\hline 3.Capuava (ex-União) & RECAP & Mauá/SP/SE & 62.898 & 1954 & Petrobras \\
\hline 4. Manguinhos & & Rio de Janeiro/RJ/SE & 14.000 & 1954 & Privada \\
\hline 5. Pres. Bernardes & RPBC & Cubatão/SP/SE & 169.825 & 1955 & Petrobras \\
\hline 6. Isaac Sabbá & REMAN & Manaus/AM/N & 45.916 & 1956 & Petrobras \\
\hline 7. Duque de Caxias & REDUC & $\begin{array}{c}\text { Duque de } \\
\text { Caxias/RJ/SE }\end{array}$ & 251.952 & 1961 & Petrobras \\
\hline $\begin{array}{l}\text { 8. Lubrificantes e } \\
\text { Derivados de Petróleo } \\
\text { do NE }\end{array}$ & $\begin{array}{l}\text { LUBNO } \\
\text { R }\end{array}$ & Fortaleza/CE/NE & 10.378 & 1966 & Petrobras \\
\hline 9. Gabriel Passos & REGAP & Betim/MG/SE & 166.051 & 1968 & Petrobras \\
\hline 10. Alberto Pasqualini & REFAP & Canoas/RS/S & 220.144 & 1968 & Petrobras \\
\hline 11. Paulínia & $\begin{array}{l}\text { REPLA } \\
\mathrm{N}\end{array}$ & Paulinia/SP/SE & 433.998 & 1972 & Petrobras \\
\hline $\begin{array}{l}\text { 12. Pres. Getúlio } \\
\text { Vargas }\end{array}$ & REPAR & Araucária/PR/S & 213.854 & 1977 & $\begin{array}{c}\text { Petrobra } \\
\text { s }\end{array}$ \\
\hline 13. Henrique Lage & REVAP & $\begin{array}{c}\text { São José dos } \\
\text { Campos/SP/SE }\end{array}$ & 251.593 & 1980 & Petrobras \\
\hline 14. Univen & & Itupeva/SP/SE & 9.158 & 2007 & Privada \\
\hline 15. Dax Oil & & Camaçari/BA/NE & 2.095 & 2008 & Privada \\
\hline $\begin{array}{l}\text { 16. Potiguar Clara } \\
\text { Camarão }\end{array}$ & RPCC & Guamaré/RN/NE & 44.658 & 2009 & Petrobras \\
\hline 17. Abreu e Lima & RNEST & Ipojuca/PE/NE & 115.009 & 2014 & Petrobras \\
\hline Total & & & 2.405 .573 & & \\
\hline
\end{tabular}

FONTE: ANP, 2018. Organização própria. 1. Dados de 2017.

7 Analisando o quadro 1 e o mapa 1, ressaltamos que um expressivo atributo do refino brasileiro é a elevada concentração espacial, pois sua construção procurou otimizar o conjunto do parque industrial do petróleo, maximizando as economias de escala na produção e, ao mesmo tempo, minimizando as deseconomias de escala na distribuição: as refinarias foram construídas em locais próximos aos primordiais centros consumidores. $O$ maior número delas, oito, localiza-se na região Sudeste, sendo que cinco concentram-se no estado de São Paulo, duas no Rio de Janeiro e uma em Belo Horizonte. A região Nordeste possui cinco refinarias, a região Sul três e a região Norte uma. 


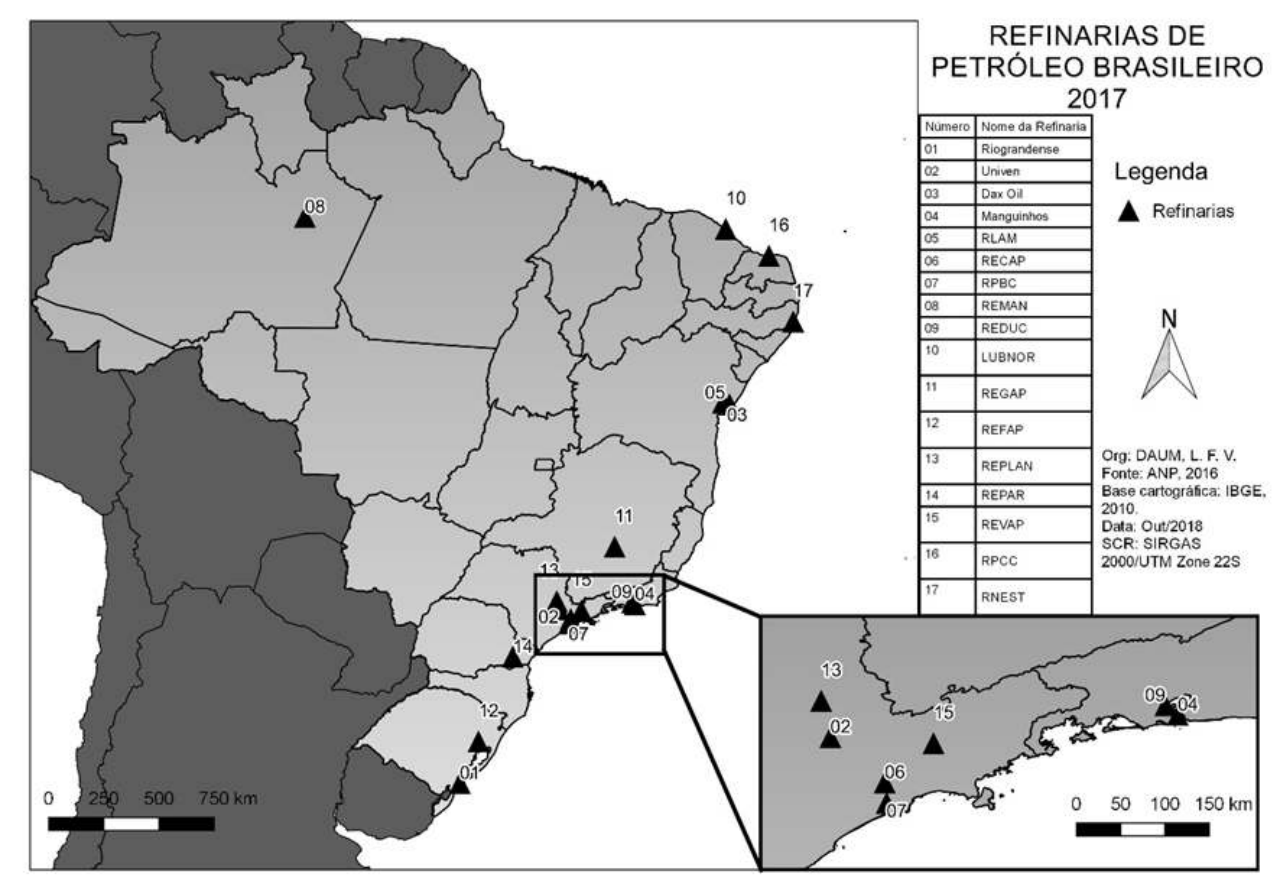

A seguir, abordamos a Petrobras Transporte S.A. (Tranpetro), pertencente a Holding Petrobras.

\section{TRANSPETRO}

Criada em 12 de junho de 1998, as principais características da Petrobras Transporte S.A. (Transpetro) são:

Principal empresa de logística e transporte do Brasil;

Maior armadora da América Latina no setor de transporte do ouro negro e derivados;

Líder nacional no transporte e no processamento de gás natural;

14 Atua ainda nas operações de importação e exportação de petróleo e derivados, gás e etanol. Com mais de 14 mil quilômetros de oleodutos e gasodutos, 47 terminais (20 terrestres e 27 aquaviários) e 56 navios (vide tabela 1), a Transpetro detém a finalidade de levar aos mais diferentes pontos do Brasil o combustível que move a economia do país. Suas operações também abastecem indústrias, termelétricas e refinarias (TRANSPETRO, 2017).

Como subsidiária integral da Petrobras, aglutina as áreas de produção, refino e distribuição da Holding Petrobras e presta serviço a diversas distribuidoras e à indústria petroquímica. Portanto, a Transpetro, tem atuação nacional, com instalações em 20 das 27 unidades federativas brasileiras. Está hoje estruturada nas seguintes áreas de negócios: Dutos e Terminais; Transporte Marítimo; e Gás Natural. No exterior, atua por intermédio da Transpetro International BV (TI BV) e coopera com a Petrobras na execução de projetos internacionais. 
Os seus 56 navios navegam pelos mares do Brasil e do mundo, transportando: biodiesel, butano, etanol, gás liquefeito de petróleo (GLP), gasolina, nafta, óleo combustível, óleo diesel, petróleo, propano e querosene de aviação. Em relação à gestão ambiental, foi a primeira frota petroleira do mundo a obter o certificado ambiental ISO 14.001 e uma das primeiras certificadas pelo cumprimento do ISM CODE, o código internacional de gerenciamento de segurança operacional do International Maritime Organization (IMO) braço marítimo da Organização das Nações Unidas (TRANPETRO, 2008).

Tabela 1. Principais números da Transpetro - 2015 a 2017.

\begin{tabular}{|c|c|c|}
\hline Image & \multicolumn{2}{|c|}{ 101CD6400000717100004EFCFB1259BD63E837F1.emf } \\
\hline Características da Transpetro & & Números \\
\hline Receita operacional bruta* & & RS 9.549 bilhões \\
\hline Lucro líquido* & & RS 1.033 bilhão \\
\hline Patrimônio liquido* & & RS 5.305 bilhões \\
\hline Carga Movimentada* & Transporte Maritimo & $\begin{array}{l}66,3 \text { milhões de toneladas } \\
\text { métricas de petróleo, derivados e } \\
\text { etanol/ano }\end{array}$ \\
\hline & Terminais e Oleodutos & $\begin{array}{l}620 \text { milhões de } \mathrm{m}^{3} \text { de petróleo, } \\
\text { derivados e etanol/ano }\end{array}$ \\
\hline & Gasodutos & 74,8 milhões de $\mathrm{m}^{3}$ de gás/dia \\
\hline Capacidade de armazenamento* & Terminais & 10.7 milhões de $\mathrm{m}^{3}$ \\
\hline $\begin{array}{l}\text { Capacidade de processamento de } \\
\text { gás* }\end{array}$ & & 19,7 milhões de $\mathrm{m}^{3} /$ dia \\
\hline Dutos** & Oleodutos & $7.655 \mathrm{~km}$ \\
\hline & Gasodutos & $7.155 \mathrm{~km}$ \\
\hline Terminais** & Terrestres & 20 \\
\hline & Aquaviários**** & 27 \\
\hline Navios*** & & 56 \\
\hline
\end{tabular}

FONTE: TRANSPETRO (2017). Elaboração: COSTA, 2017.

* Dados de 2015

** Dados de junho de 2016.

*** Dados de agosto de 2017

**** Sendo 3 terminais de regaseificação de Gás Natural Liquefeito (GNL): Pecém (CE), TRBA (BA) e Baía de Guanabara (RJ).

Destacamos que está ocorrendo uma renovação da frota, através do Programa de Modernização e Expansão da Frota da Transpetro (PROMEF). Este Programa, até 2015, previa a construção de 46 novos petroleiros, os quais irão acrescentar mais de 3 milhões de toneladas de porte bruto (TPB) à frota da Transpetro. Em 2007 foram licitados os primeiros 26 navios, que começaram a serem construídos no Brasil, com um índice de $65 \%$ de nacionalização. O investimento de US\$ 2,48 bilhões atraiu novos investidores para o setor da indústria naval; e, encorajou pedidos de outros armadores. Salientamos que o Brasil iniciou o ano de 2008 ocupando o $10^{\circ}$ lugar no ranking mundial de construtores de navios (TRANSPETRO, 2008).

Porém, em outubro de 2016, a empresa anunciou que encontra-se em um processo de otimização de custos e gestão. Neste processo, decidiu-se abortar a diretriz de contratar a construção de navios próprios com estaleiros nacionais, desfazendo a política dos 
governos Lula (2003-2010) e Dilma (2011-2016) de utilizar a demanda da Petrobras para incentivar a indústria naval.

Portanto, a Transpetro cancelou a contratação de 17 navios previstos no PROMEF. São embarcações que nem começaram a ser construídas e todas as encomendas tiveram contratos rescindidos. O PROMEF era um dos principais programas da Transpetro sob a gestão de Sérgio Machado (ex-presidente da subsidiária entre 2003 a 2014).

O programa previa a fabricação de 46 petroleiros. Desse total, 17 foram construídos e entregues. Em outubro de 2016 nove estavam em construção, sendo aguardadas pela Transpetro. Três embarcações que estavam em construção no estaleiro Eisa Petro-1(Rio de Janeiro) estão com situação indefinida, após o fornecedor pedir recuperação judicial. Segundo Antônio R. S. Silvino (atual presidente da empresa) esses pedidos podem tanto ser canceladas quanto repassadas para outros estaleiros (NEDER; NUNES, 2016).

21 Ainda conforme Silvino, o cancelamento de 17 pedidos não significa a diminuição na capacidade de operação. $O$ plano é fretar navios para dar conta da demanda da Petrobrás e de outras empresas, já que o foco de expansão da Transpetro agora vai além de atender a controladora. "O fato de ter cancelado 17 navios não quer dizer que não vamos ter navios. Estamos avaliando contratar navios a casco nu", disse, comparando com a frota de caminhões da Transpetro, da qual 355 são de terceiros. "Não é terceirização. $O$ navio é contratado, mas eu tripulo e presto o serviço", disse (NEDER; NUNES, 2016).

Segundo ele, a Transpetro está em processo acelerado de otimização de custos e gestão, para aumentar a competitividade. "Vamos migrar de uma atuação muito focada na Petrobras para também atender ao mercado", disse Silvino.

23 A Transpetro é responsável pela operação e manutenção de mais de $7.100 \mathrm{~km}$ de gasodutos e pelo Polo de processamento de gás de Cabiúnas (TECAB), em Macaé (RJ), o maior do Brasil. Esta malha integra as regiões Sudeste e Sul ao Nordeste, possibilitando enorme flexibilidade operacional, além de abranger o transporte de gás natural de Urucu a Manaus, na região Norte. Por esta rede são escoados $75 \%$ de todo o gás natural consumido no Brasil (TRANSPETRO, 2017).

O consumo deste produto tem ampliado consideravelmente nos últimos anos. Estima-se um crescimento médio anual, entre 2010 e 2015 , de $12,4 \%$. E a expectativa é que o fornecimento de gás natural alcance a 149 milhões de $\mathrm{m}^{3} / \mathrm{dia}$, sendo 134 milhões de $\mathrm{m}^{3}$ movimentados pelos gasodutos operados pela Companhia.

O TECAB é considerado uma das mais importantes e complexas unidades da Transpetro. Dentre suas atividades está a produção e fornecimento de gás liquefeito de petróleo (GLP) ${ }^{3}$ a distribuidoras, além de matéria-prima para abastecimento do Polo Gás-Químico de Duque de Caxias, por meio da Refinaria Duque de Caxias (REDUC).

26 A malha de gasodutos da Transpetro compreende 68 linhas (entre gasodutos e ramais), estações de compressão, pontos de recebimento (entre os quais dois terminais de GNL), pontos de entrega e atravessa 306 municípios. Atualmente, a capacidade de transporte é de 100 milhões de $\mathrm{m}^{3} /$ dia, com crescimento previsto a partir da entrada em operação até 2020 de novas estações de compressão (TRANSPETRO, 2017).

27 A Transpetro também criou o Centro Nacional de Reparos de Dutos (CREDUTO) e é cofundadora do Centro de Tecnologia em Dutos (CTDUT), o primeiro centro tecnológico compartilhado de dutos da América Latina. Ademais, o Centro de Pesquisas e Desenvolvimento Leopoldo Américo Miguez de Mello (CENPES) é o principal parceiro 
tecnológico da Transpetro, desenvolvendo tecnologias sob medida aos intuitos da empresa.

Destacamos a criação em 2002 do Centro Nacional de Controle Operacional (CNCO); o qual monitora e controla, de forma centralizada, toda a malha de dutos que opera. Localizada em sua sede, no Centro do Rio de Janeiro, a unidade funciona 24 horas por dia. Possui equipamentos de alta tecnologia, capazes de supervisionar, com agilidade e segurança, os mais de 14 mil quilômetros de oleodutos e gasodutos que cruzam o Brasil.

O sistema operacional utilizado pelo CNCO permite ligar e desligar bombas e compressores, abrir e fechar válvulas, alterar pontos de operação de malhas de controle de pressão e vazão, entrada e saída de combustíveis de terminais e refinarias e consumidores finais e desvio de produtos para outro sistema de oleodutos (TRANSPETRO, 2008).

Os terminais são instalações fixas que aglutinam um conjunto de equipamentos $\mathrm{e}$ estruturas destinadas às operações de armazenamento, transferência e distribuição de petróleo, derivados, etanol e GLP. Aos terminais conecta-se a malha dutoviária existente no Brasil. O nosso país é servido por uma rede de oleodutos que possui $7.882 \mathrm{~km}$ de extensão. Somando a malha completa associada à indústria do petróleo (que abrange também o transporte de gás natural e outros produtos), esta se estende por $19.715 \mathrm{~km}$. As linhas destinadas à movimentação de gás natural são as mais significantes entre os produtos transportados, e correspondem a $60 \%$ do total deste sistema de engenharia (ANP, 2013).

Para viabilizar a movimentação de petróleo, derivados e etanol no território nacional, o Brasil dispunha de 108 terminais autorizados em 2015, sendo nove centros coletores de etanol (com 21 tanques), 55 terminais aquaviários (com 1.416 tanques) e 45 terminais terrestres (com 486 tanques), totalizando 1.923 tanques. A capacidade nominal de armazenamento foi de cerca de 13,5 milhões de $\mathrm{m}^{3}$, dos quais 5,3 milhões de $\mathrm{m}^{3}$ (39,3\% do total) destinados ao petróleo, 7,8 milhões de $\mathrm{m}^{3}$ (57,7\% do total) aos derivados e ao etanol, e $412,4 \mathrm{mil} \mathrm{m} 3$ (3,1\% do total) ao GLP. (ANP, 2016, p. 115).

31 Os terminais aquaviários concentravam a maior parte da capacidade nominal de armazenamento (9,4 milhões de $\mathrm{m}^{3}, 69,4 \%$ do total) e o maior número de tanques autorizados (1.416, 73,6\% do total).

O óleo bruto entregue aos terminais petroleiros provém das regiões produtoras de petróleo, nacionais ou estrangeiras quando o mesmo é importado. Neste caso, o objetivo dos terminais é receber o óleo (nacional ou importado e destiná-lo para as unidades refinadoras, onde são executados os processos de transformação para uma gama de outros produtos derivados, principalmente os combustíveis. No caso do óleo produzido no Brasil, alguns destes mesmos terminais funcionam também como entreposto de transferência para navios petroleiros de porte apropriado para fazer transporte de exportação ou cabotagem para terminais de menor porte (TRANPETRO, 2017).

Os terminais aquaviários são as estruturas que permitem a movimentação de petróleo e derivados, conjuntamente com o transporte marítimo, fluvial ou lacustre de petróleo e derivados. Caracterizam-se, portanto, pela presença de estruturas náuticas, voltadas para movimentação e operação de embarcações. Tais operações dediquam-se primordialmente a transferência (entrega e recebimento) dos produtos, e contam com estruturas tais como píeres, monobóias ou quadro de bóias, linhas de transferência (dutovias), entre outras. Estas instalações possibilitam as operações de transferência de petróleo e derivados entre 
as embarcações petroleiras e os terminais. A depender da operação executada em cada terminal, suas estruturas são apropriadas a certos tipos de embarcações: barcaças, cabotagem, de longo curso, de longo curso; além das embarcações que fornecem apoio operacional (LIMA, 2015).

Logo, o transporte e armazenamento aquaviários são elos estratégicos dos fluxos do petróleo no território. Ao abranger uma relevante fração da produção em suas estruturas e assegurar o movimento contínuo dos produtos, consistem em elementos fundamentais de origem e destinos dos fluxos do petróleo. Baseiam-se os essenciais elos de conexão entre as fases de produção, refino e o mercado de derivados. Dessa forma, instauram-se as condições decisivas do fluxo entre as diversas atividades do circuito espacial da produção.

No decorrer do trabalho sobre o refino desse hidrocarboneto no Paraná (e Refinaria Presidente Getúlio Vargas/REPAR) ${ }^{4}$ visitamos dois terminais aquaviários que possuem operações com a REPAR. São eles: Terminal Aquaviário de Paranaguá/TEPAR (PR) e Terminal Aquaviário de São Francisco do Sul/TEFRAN (SC). ${ }^{5}$

36 Em seguida, abordamos as relações socioespaciais entre a REPAR e o município de Araucária.

\section{Relações entre Araucária (PR) e refinaria presidente Getúlio Vargas (REPAR)}

O crescimento urbano de Araucária se intensificou com a alteração na estrutura produtiva do município. Criado pelo decreto estadual $\mathrm{n}^{\circ} 40$ de 11/02/1890, apresentava a erva mate como principal produto para consumo local e mais tarde para exportação até os anos 1980. Até a década de 1960, a principal atividade do município era a agricultura. A partir de 1973, com o início da construção da REPAR e com a implantação do CIAR ${ }^{6}$, iniciou-se um processo de crescimento bastante acentuado e uma inversão no quadro populacional (vide tabela 2), econômico e social do município, onde a população urbana passou a superar a rural com a vinda de um contingente populacional de vários pontos do país, e a economia que se baseava na agricultura e pecuária, passou a ser predominantemente industrial/urbana.

38 Portanto, Araucária foi tomada por uma onda de otimismo e esperança de que aumentasse o número de empregos e houvesse uma melhoria das condições de vida da população por ocasião da instalação da refinaria da Petrobras. Entretanto, com o desenvolvimento do polo petroquímico desvinculado da realidade local, devido ao tipo de indústria instalado, tipo de produção, tecnologia e mão-de-obra, formaram-se dois tipos de comunidades distintas: a local e a do parque industrial em formação. Ocorreu um expressivo fluxo migratório e ainda acontece um crescimento elevado da população do município (ver tabela 2). 
Tabela 2. Evolução da População de Araucária (PR) - 1960-2010

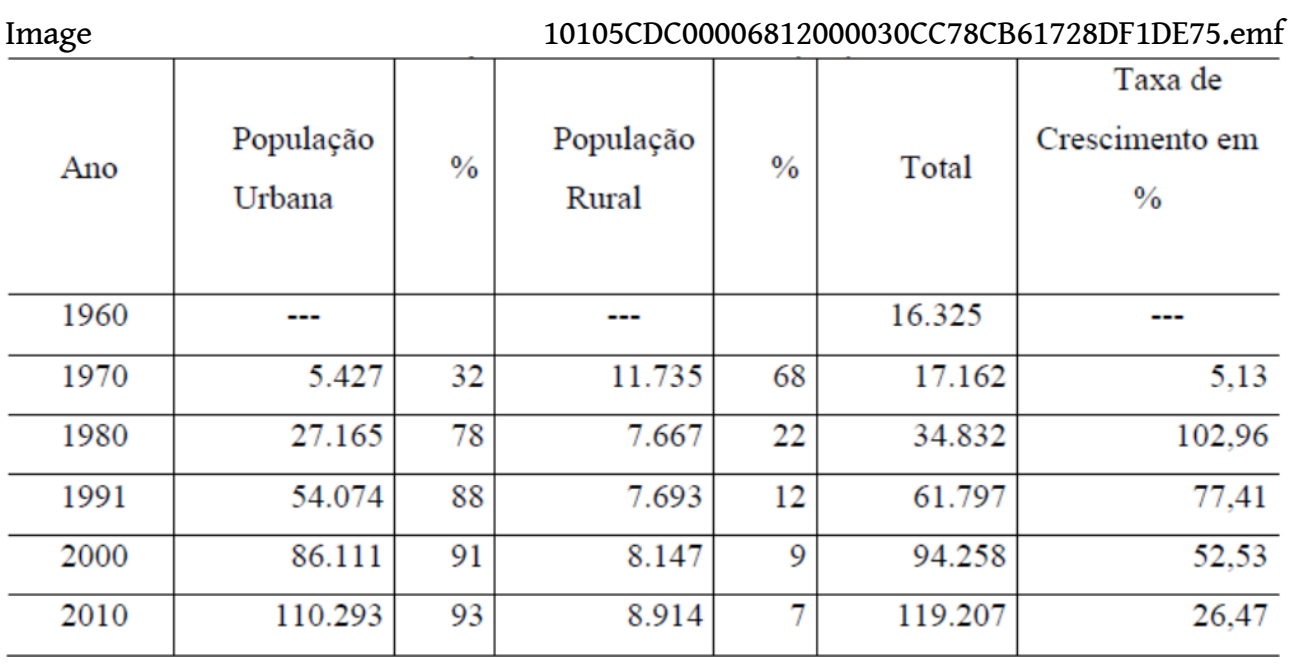

FoNTE: IBGE - Censos Demográficos de 1960, 1970, 1980, 1991, 2000 e 2010 (formulação própria).

Analisando a tabela 2, verificamos elevados índices de crescimento demográfico em Araucária, a partir dos anos 1970, devido à implementação da REPAR (em 1977); principalmente nas décadas de 1970 (102,96 \%) e de 1980 (77.41\%); composto pela urbanização do município e pela chegada expressiva de migrantes.

O crescimento industrial de Araucária pode ser dividido em três fases: a primeira, nas primeiras décadas do século $\mathrm{XX}$, foi mais voltada ao consumo interno do município e arredores. Eram serrarias, cervejarias, olarias, engenhos de erva-mate e fábricas de barricas, usadas para transporte e armazenamento de mate beneficiado. A segunda foi a da produção de linho, com destaque para a fábrica São Manoel, filial da Fiação São Patrício (SP), funcionando entre 1940 e 1961. E a terceira começa em 1973 com o início da construção da REPAR e a implantação do CIAR (vide mapa 2); ocasionando um acelerado processo de industrialização a partir do final dos anos 1970.

41 A opção da empresa Petrobras, pelo Paraná atendeu ao mesmo tempo interesses políticos e objetivos estratégicos que correspondiam aos interesses e à diversificação da economia regional. Segundo Lourenço (2003, p. 18)

A vinda e a consolidação da Petrobras no Paraná estão associadas à combinação do projeto de aprofundamento do ciclo brasileiro de substituição de importações com o desejo de industrialização da sociedade regional, capitaneado e viabilizado durante as passagens do ex-governador Ney $\mathrm{Braga}^{7}$, tanto no executivo estadual quanto no âmbito federal, como Ministro do Estado.

Mapa 2. Localização da Cidade Industrial de Curitiba (CIC) 


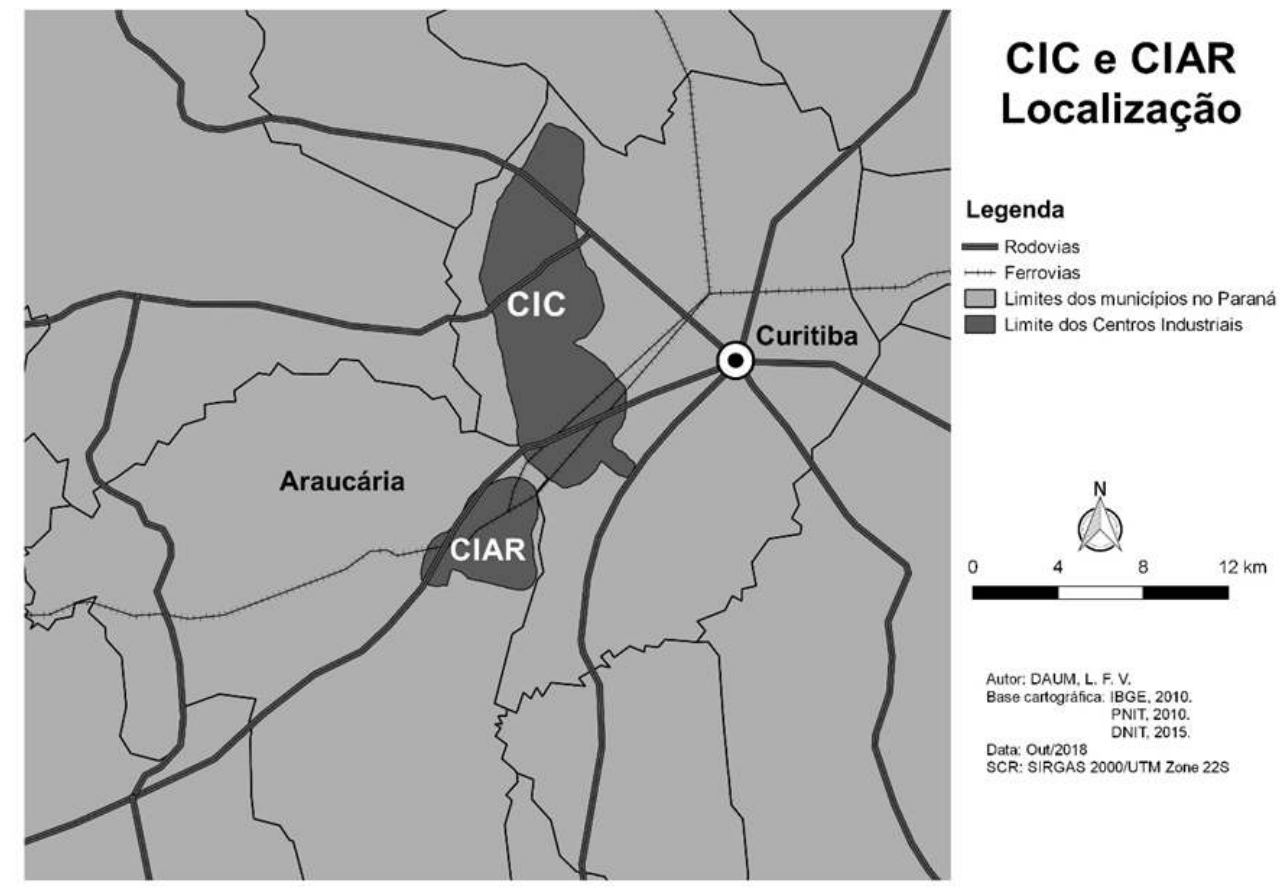

FONTE: Adaptado de SILVA, 2006, p. 21

42 Na segunda metade dos anos 1970 e inserido no II Plano Nacional de Desenvolvimento/ PND (1975-79), o Paraná vivenciou momentos de intensa pressão política através do governador Ney Braga, ou de importantes técnicos paranaenses designados por ele em postos-chave da administração federal, principalmente entre 1975 a 1978.

43 Apesar da forte oposição/influência exercida pela Federação das Indústrias do estado de São Paulo (FIESP) com o fim de não se alterar a política industrial do país; o Paraná conseguiu implantar parques industriais modernos, como: os complexos metalmecânico e de refino de petróleo no Aglomerado Metropolitano de Curitiba (AMC).

Nesse sentido, a definição do projeto da refinaria de Araucária, constitui exemplo acabado da influência das gestões de natureza política na garimpagem de empreendimentos-âncora pelos Estados de industrialização tardia. A escolha do Paraná como opção locacional se deu depois de exaustivos lances de negociação política entre o governo Geisel e os três governadores dos estados do Sul. (LOURENÇO, 2003, p. 19).

A ampliação da capacidade produtiva e a modernização do Centro-Sul estariam baseadas na instalação e/ou consolidação do polo petroquímico no Rio Grande do Sul, no parque siderúrgico em Santa Catarina e na refinaria de petróleo e desenvolvimento da Cidade Industrial de Curitiba (CIC) no Paraná.

A partir do momento em que a Petrobras define que o Paraná iria receber uma refinaria de petróleo, a cidade de Araucária passa a fazer parte da industrialização no estado. Dessa forma, possibilitando que o setor administrativo do município realizasse a criação do Centro Industrial de Araucária (CIAR) para receber as instalações da refinaria.

A localização do CIAR foi estrategicamente em uma área nordeste do território municipal, dando continuidade à Cidade Industrial de Curitiba (CIC) definida por meio de legislação urbanística, sendo de uso prioritário para fins industriais. Sua área inicial é de 
aproximadamente 46.137.500,00 m²; estando sua localização ligada ao fácil acesso aos Mercados Comuns do Sul (MECOSUL). Ou seja, a área foi destinada a sediar novas instalações de empresas voltadas para agroindústria e a petroquímica; sendo que seu sítio encontra-se próximo do Aeroporto Internacional Afonso Pena (São José dos Pinhais) e com uma boa acessibilidade para o Porto de Paranaguá; dessa forma, facilitando as exportações e importações do município.

Nesse período de instalações da Petrobras, além das empresas ligadas à cadeia de gás e petróleo, podem-se destacar as seguintes empresas instaladas em Araucária: Importação, Exportação e Indústria de Óleos Ltda. (IMCOPA), Indústria de Plásticos Ltda. (PARNAPLAST), Indústria e Comércio de Adesivos Ltda. (ADESI), BERNECK Aglomerados S/ A, Construções Metálicas S/A (BRAFER), Companhia de Celulose e Papel do Paraná (COCELPA), Móveis e Decorações (EXCLUSIF), Indústria Brasileira de Lápis S/A (LABRA), BUFFET RISOTOLANDIA Ltda., que fazem parte até os dias atuais, do complexo industrial araucariense. (SKRZYPNIK, 2009).

Baseado na pesquisa sobre o Cadastro Industrial da FIEP $^{8}$ e confecção de tabelas, observamos que Araucária possui 168 empresas industriais (dados de 2014); onde se diversificam em variados setores como: Fabricação de Produtos de Metal, exceto Máquinas e Equipamentos; Fabricação de Máquinas e Equipamentos; Fabricação de Produtos de Borracha e de Material Plástico; Fabricação de Produtos Químicos; Fabricação de Celulose, Papel e Produtos de Papel; Fabricação de Produtos Alimentícios (FIEP, 2015). Do total das 168 fábricas do município, 60 dessas, se localizam próximas à refinaria da Petrobras, no bairro Thomaz Coelho; ou seja, $35,71 \%$, e as demais indústrias espalhadas pelos bairros da cidade (vide tabela 3).

Tabela 3. Principais Bairros industriais de Araucária (PR) - 2014

\begin{tabular}{lc} 
Image & 1005C35400003D1000001D3AC5970D66320380D7.emf \\
\hline Bairros & Número de fábricas \\
\hline 1. Thomaz Coelho & $\mathbf{6 0}$ \\
2. Estação & 14 \\
3. Chapada & 14 \\
4. Barigui & 13 \\
5. Capela Velha & 11 \\
6. Tindiquera & 09 \\
7. Outros bairros & 47 \\
\hline Total & $\mathbf{1 6 8}$ \\
\hline
\end{tabular}

FONTE: FIEP. Cadastro das indústrias 2014. 2015.

ORgANIZAÇÃo: LARA, S. E COSTA, P., 2015.

A REPAR começou a ser construída em 1973 e entrou em operação no dia 27 de maio de 19779. Já no final dos anos 1970, a unidade processava $24 \mathrm{mil} \mathrm{m}^{3}$ de petróleo por dia. $\mathrm{Na}$ década de 1980, a refinaria amplia suas áreas verdes e instala estações de medição da qualidade do ar. Responsável por 9,34\% da produção nacional de derivados de petróleo; refinando 162.645 barris por dia (ANP, 2018) ${ }^{10}$. A REPAR destina 85\% de seus produtos aos 
estados do Paraná, Santa Catarina e Mato Grosso do Sul, além da região sul de São Paulo. Os demais $15 \%$ completam o abastecimento de outras regiões ou são exportados (vide mapa 3).

A REPAR chegou a ter em atividade 11 mil profissionais no período de sua construção. Ela está localizada no município de Araucária ${ }^{11}$, a 25 quilômetros de Curitiba. A Refinaria é a principal empresa do setor químico paranaense e a maior fábrica do sul do País. Em relação à distribuição de sua produção, notamos que ela se dá principalmente por dois terminais marítimos (Terminal Aquaviário de São Francisco do Sul/SC - TEFRAN e Terminal Aquaviário de Paranaguá/PR - TEPAR) e por um poliduto (Guaramirim-ItajaíFlorianópolis) que interliga a refinaria ao estado de Santa Catarina.

Mapa 3. Cadeia logística da Refinaria Presidente Getúlio Vargas (REPAR) - Araucária (PR).
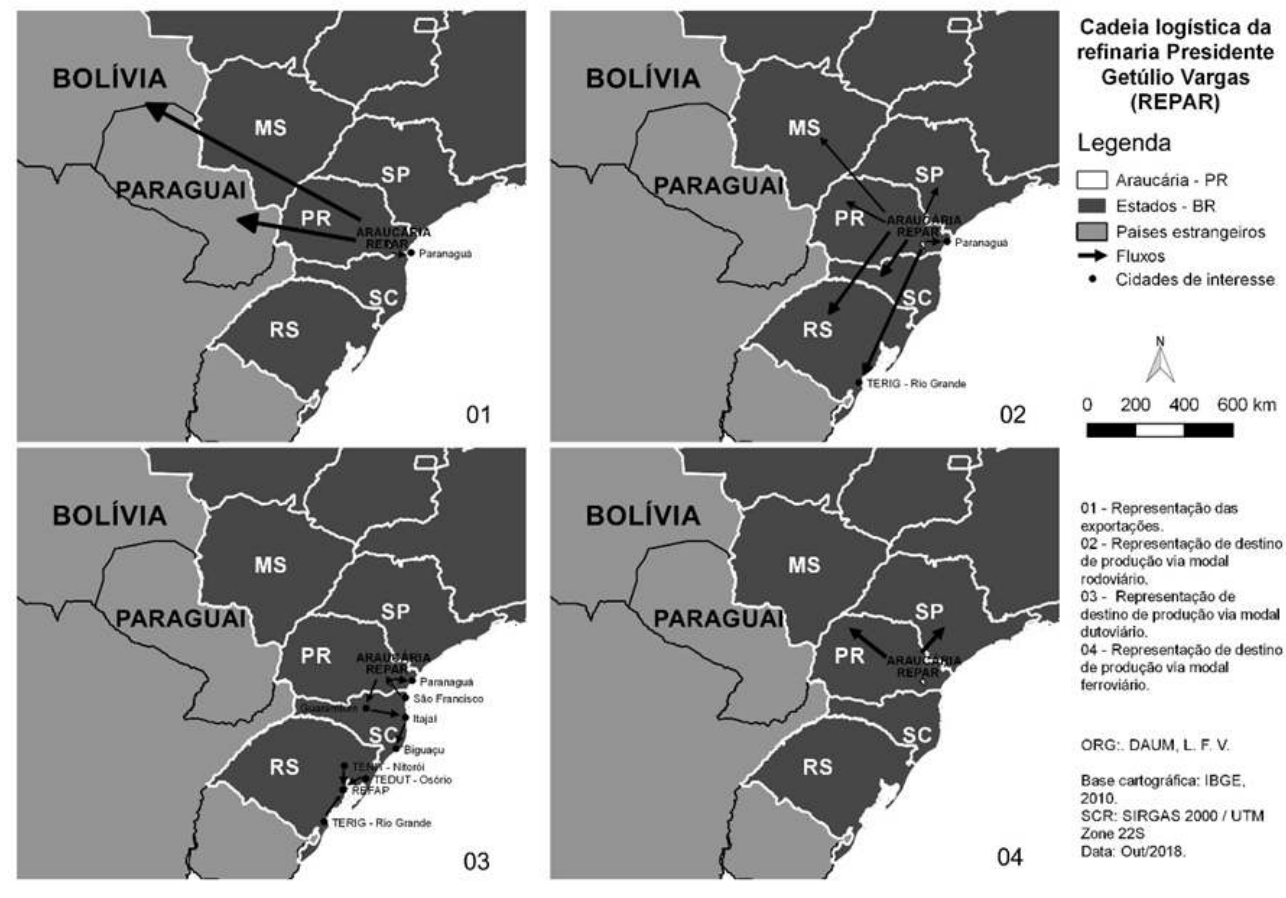

FONTE: Adaptado de SILVA, 2013.

51 A instalação da Repar em 1977 no Paraná, até então um estado predominantemente agrícola, propiciou na região de Curitiba e Araucária, a criação de parques industriais que resultaram em atratividade para instalação de novas empresas industriais e de serviços, notadamente para o Aglomerado Metropolitano de Curitiba (AMC). Sua importância para a arrecadação de impostos do estado é bastante relevante, pois a participação da Refinaria na contribuição do ICMS ${ }^{12}$ do Paraná é de aproximadamente $16 \%$, ocupando o primeiro lugar entre os contribuintes do estado. O repasse anual de aproximadamente US\$900 milhões em ICMS ao governo, dentre os tributos que recolhe, coloca o município de Araucária como o segundo do estado, perdendo apenas para a capital - Curitiba.

Os produtos da Refinaria de Araucária são: Gasolina, Querosene, Combustível Marítimo ( bunker), Gás Liquefeito de Petróleo (gás de cozinha), Diesel Automotivo, Nafta Petroquímica, Óleos Combustíveis, Asfalto Diluído Asfalto, Matéria-Prima para Fertilizantes, Solventes, Enxofre Sólido e Propeno. 
Sobre o Aglomerado Metropolitano de Curitiba (AMC), observamos que ele é formado por doze municípios, sendo eles: Curitiba, Almirante Tamandaré, Araucária, Campina Grande do Sul, Campo Largo, Campo Magro, Colombo, Fazenda Rio Grande, Pinhais, Piraquara, Quatro Barras e São José dos Pinhais (ver mapa 4). O AMC corresponde aos municípios que fazem fronteira (e/ou que estão geograficamente próximos) com Curitiba e que adquiram maior importância pelo processo de desconcentração industrial que originou essa dimensão metropolitana que melhor apreende toda a realização local (GARCIA, 2006). Em 2010, a população residente no AMC era de 2.939.141 habitantes, representando $28 \%$ do total da população do estado. Sua população urbana de 2.803 .396 habitantes representava $31 \%$ do total da população urbana paranaense. Portanto, essa região do Paraná - onde se localiza a Refinaria de petróleo paranaense - concentra a população desse estado, e, também, caracteriza-se por ser a região com maior dinamismo econômico.

Mapa 4. Localização do Aglomerado Metropolitano de Curitiba (AMC).

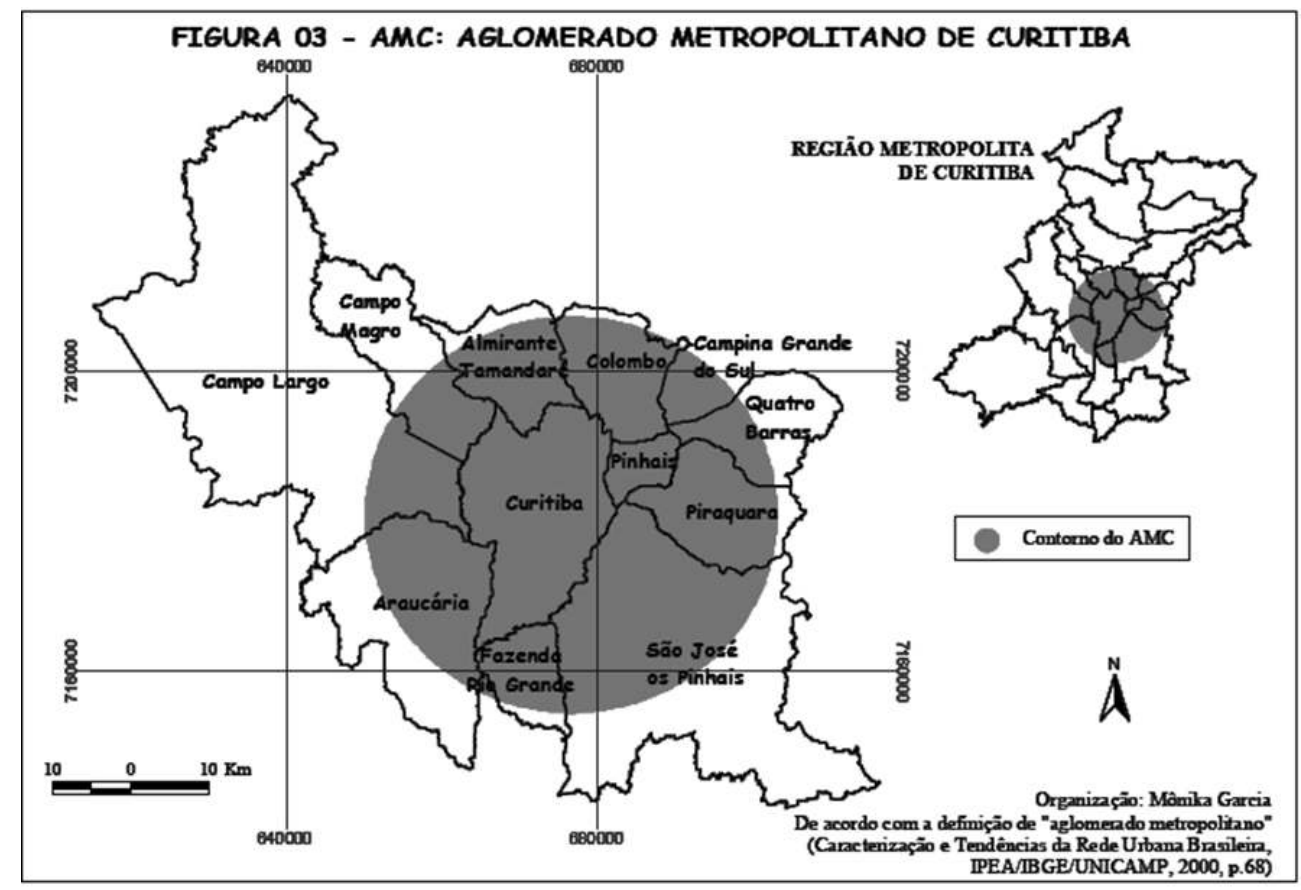

FONTE: Garcia, 2006

Com o desenvolvimento da presente pesquisa, verificamos que a partir da década de 1970 ocorreram algumas consequências em relação ao processo repentino de urbanização, e também pelo fato que as cidades não estavam preparadas para essa grande leva de imigrantes, onde o resultado se deu em uma ocupação maciça de áreas periféricas e degradadas. Esse leque de mudança se deu com a vinda de empresas multinacionais para o estado, principalmente ligadas ao complexo metal mecânico.

Outra disparidade socioeconômica no AMC pode ser percebida, fazendo-se um comparativo de dois municípios que são separados por apenas $30 \mathrm{~km}$, os quais são Araucária e Piraquara. Apesar das proximidades, um abismo separa os dois municípios que representava os extremos opostos do desenvolvimento econômico paranaense no ano de 2014. Araucária era cidade com o maior PIB per capita do estado ${ }^{13}, 6$ vezes maior do que da vizinha Piraquara que detinha o segundo pior valor dentre os 399 municípios do Paraná, com R $\$ 10.679^{14}$ (IPARDES, 2015). A indústria instalada no 

sempre traduz em benefícios e melhorias para a população. Concomitantemente, Souza (1998) aborda que fenômenos como: verticalização, realização de obras viárias, expansão horizontal do tecido urbano, muitas vezes são tidas pela maioria das pessoas como processos de desenvolvimento urbano, porém, avolumam-se as queixas; cresce a consciência que muitos desses acontecimentos, associam-se a coisas indesejáveis como grandes impactos negativos sobre o meio ambiente, perda de qualidade de vida para muitos; pois, com os benefícios diluindo cada vez mais para beneficiar a parcela minoritária da população. Sobre a instalação da Cidade Industrial de Curitiba (CIC), Oliveira (2001, p.63) diz: "De nada adianta o governo se vangloriar do caráter não poluente das indústrias instaladas na CIC (...), pois são nos municípios vizinhos que se dirigem todas as mazelas e problemas"; incluindo-se, portanto, a cidade de Araucária.

61 O caso de Araucária no cenário da industrialização é repugnante, já que possui baixos salários em que os trabalhadores são considerados produtivos marginalizados, vivendo aquém das condições que poderiam ser relacionadas a de uma população que vive em um município "rico", visto que chefes de famílias apresentavam em 2000 menos de quatro anos de estudo e rendimento médio de até dois salários mínimos (NEGRELLI, 2004). ${ }^{16}$

62 O município de Araucária apresenta uma história típica, pois seu crescimento populacional atrelado a sua industrialização dá à cidade uma característica peculiar. Com essa demanda populacional, reconfiguram-se as organizações sociais e marca a necessidade da reestruturação de serviços essenciais à população como educação, saúde, transporte e moradia para atender a população. Araucária continua com graves problemas sociais, destacando-se: vazamentos, contaminantes químicos, problemas ambientais e baixos salários. 0 que se 
conclui é que o processo de industrialização trouxe benefícios, mas que não foram e não são repartidos igualmente para a população.

64 A seguir, versamos sobre os terminais aquaviários da Petrobras que atendem a REPAR.

\section{Terminais aquaviários de Paranaguá (TEPAR) e São Francisco do Sul (TEFRAN)}

65 O Terminal Aquaviários de Paranaguá (TEPAR) é interligado com a Refinaria Presidente Getúlio Vargas (Repar) por modais rodoviário e ferroviário para escoamento de derivados escuros. Para derivados claros, utiliza o poliduto bidirecional Oleoduto AraucáriaParanaguá (Olapa). ${ }^{17}$ Opera também fornecimento de bunker para navios no Porto de Paranaguá.

66 O TEPAR ocupa uma área de mais de $182 \mathrm{mil} \mathrm{m}^{2}$, em um complexo que abrange: dois píeres para atração de navios, uma estação ferroviária, 34 unidades de armazenamento (31 tanques para produtos e três esferas para gás), um laboratório de testes e um centro de combate a emergências, entre outros. Esse terminal tem capacidade para armazenar até (TRANSPETRO, 2007 e 2017):

$67194.602 \mathrm{mil} \mathrm{m}^{3}$ de derivados de petróleo, álcool e biodiesel;

68 E $9.532 \mathrm{~m}^{3}$ de Gás Liquefeito de Petróleo.

69 Esse complexo de modais de transporte atua no mercado regional e, também, detém função relevante nas operações de exportação e importação da Petrobras, regulando os estoques da REPAR de: bunker (combustível para navio), diesel, gasolina, GLP, metanol, $\mathrm{MTBE}^{18}$, nafta e o óleo combustível.

70 Normalmente os terminais são o apoio de uma refinaria, conduzindo os derivados para o refino em outras unidades através de navios, no caso da refinaria precisar fazer manutenção de seus tanques, ou em uma unidade de refino, sem poder refinar e não tendo produto para estocar, sem prosseguir com suas movimentações (COSTA, 2012).

71 O TEPAR - que passou a ser operado pela Petrobras em 1/02/1977, incorporando as instalações das empresas Shell, Atlantic, Ipiranga, Texaco e Esso - foi repassado a Tranpetro em maio de 2000 e é uma das unidades mais complexas da empresa, por deter interfaces com quatro diferentes modais: marítimo, dutoviário, rodoviário e ferroviário. Seu principal píer tem dois berços. O externo, com calado de 11,59 metros de profundidade, pode receber navios com capacidade de 45 mil toneladas de porte bruto (TPB) e 200 metros de comprimento. Por sua vez, o berço interno, com calado de 10,6 metros, recebe embarcações com até 190 metros de comprimento e 35 mil TPB (TRANSPETRO, 2007 e 2017). Destacamos, que esse terminal de Paranaguá só comercializa derivados de petróleo. A Baía de Paranaguá apresenta características de assoreamento; impossibilitando que os navios petroleiros - de maior calado - atraquem na mesma. 0 petróleo que abastece a REPAR é proveniente do Terminal Aquaviário de São Francisco do Sul/TEFRAN (SC); e, sendo transportado por oleodutos até a refinaria.

72 Uma das atividades de relevância do TEPAR é o fornecimento do bunker que abastece os navios que circulam no Porto de Paranaguá, um dos mais movimentados do Brasil e o principal do país para a exportação de grãos. 0 píer secundário do terminal é destinado exclusivamente às barcaças que vão abastecer os navios. Como exemplo, podemos citar o 
mês de maio de 2006, onde esse fornecimento através das barcaças alcançou mais de 68 mil $\mathrm{m}^{3}$ de combustível (TRANSPETRO, 2007).

73 Outra característica desse terminal é a moderna plataforma ferroviária; a qual é totalmente coberta, possibilitando que 20 vagões descarreguem simultaneamente. Acrescentamos que esse modal apresenta significativa participação nos resultados do TEPAR. Em 2005, o terminal recebeu, por esse modal, mais de $840 \mathrm{mil} \mathrm{m}^{3}$ de óleo combustível.

74 Um dos mais modernos laboratórios da Transpetro está sitiado no TEPAR. Ocupando uma área de $300 \mathrm{~m}^{2}$, realiza, por mês, cerca de 2.600 análises, incluindo testes de: corrosão ao cobre, destilação, densidade, teor de hidrocarbonetos, ponto de ebulição, viscosidade, análises de águas de caldeiras, pressão de vapor em gasolina e GLP, enxofre, pH em álcool e tolerância à agua. Ademais, oferece estágio para estudantes de cursos da área de Química.

75 Na área social, o TEPAR, em parceria com a prefeitura de Paranaguá, realizou melhorias na rede de drenagem pluvial, para inibir as frequentes inundações da Vila Becker, comunidade vizinha ao terminal. A empresa também foi parceira no projeto da implementação do aterro Sanitário de Paranaguá, que substituiu o lixão.

76 Nos últimos anos, foram executadas inovações na área de segurança operacional, meio ambiente e saúde no terminal. Dentre elas, destacamos:

A cobertura da plataforma ferroviária, a criação do Centro de Respostas a Emergências, as instalações de um píer flutuante para embarcações de emergência, da estação de odorização de GLP e do pátio de resíduos temporários, a ampliação do laboratório e, por fim, a construção de uma "rua" sobre o mar. A chamada Rua F foi construída na face norte do terminal, para ampliar as rotas de fuga usadas em caso de emergência. Como não havia espaço para a construção convencional de uma rua, ela foi edificada sobre a água, como um píer. (TRANPETRO, 2007, p. 11).

77 O Terminal Aquaviário de São Francisco do Sul/SC (TEFRAN) recebe petróleo de navios por monobóia e envia a matéria-prima por oleodutos submarinos até o terminal, onde é armazenada. Posteriormente, transfere petróleo bruto pelo Oleoduto Santa CatarinaParaná (OSPAR) para a Refinaria Presidente Getúlio Vargas (REPAR). ${ }^{19}$

78 O TEFRAN possui: 6 tanques para armazenamento de petróleo, um laboratório de testes e um centro de combate a emergências, horto florestal, entre outros. Esse terminal tem capacidade para armazenar até $466.622 \mathrm{~m} 3$ de ouro negro.

79 A respeito das ações sociais e ambientais, a Transpetro adquiriu 174 lotes e 56 casas em área adjacente ao Terminal. Após a aquisição de uma área de $70.000 \mathrm{~m}^{2}$, a TRANSPETRO convidou a ONG UNIBIO ${ }^{20}$ para assumir o compromisso de recuperar a área degradada $\mathrm{e}$ desenvolver atividades socioambientais com a comunidade (denominada de Horto Florestal). $O$ projeto teve sua inauguração em junho de 2004 sendo designado "Projeto Ecológico Cinturão Verde". Para a sua instalação duas residências foram recuperadas e destinadas ao Museu de Zoobotânica e Casa de Recepção; foram executadas diversas obras, como (UNIBIO, 2017):

Construção de 520m de trilhas elevadas; horto florestal e estufa para a produção de mudas;

Implantação da horta comunitária;

Implementação do projeto de revegetação (clonagem vegetal);

Plantio de 4.000 essências nativas; 

Araucária revelam que a cidade perdeu a característica de tão somente "município ruralagrário"; vivenciando processos acelerados de industrialização e urbanização. Nas décadas de 1980 e 90 começa a se consolidar o Polo Petroquímico de Araucária. Porém, apesar de todo este crescimento econômico, verificado principalmente a partir dos anos 1970, Araucária continua com graves problemas sociais.

\section{BIBLIOGRAPHY}

Fonte : 
CARVALHO, Ernani F. de. Entrevista concedida a Pierre Costa em julho de 2013, no Rio de Janeiro.

COSTA. Pierre. Visita técnica ao Terminal Aquaviário de Paranaguá (TEPAR) - 29/08/2013.

. Visitas técnicas à Refinaria Presidente Getúlio Vargas (REPAR) - Araucária (PR) $30 / 09 / 2011$ e $12 / 09 / 2013$

. Visitas técnicas ao Porto de Paranaguá (PR) - 30/09/2011, 12/09/2013 e 25/04/2014.

. Visita técnica ao Instituto Paranaense de Desenvolvimento Econômico e Social (IPARDES) 25/04/2014.

. Visita técnica ao Terminal de São Francisco do Sul (TEFRAN) - 10/06/2015.

SILVA, Iuri B. Palestra sobre a Refinaria Presidente Getúlio Vargas. Araucária: REPAR, 12/09/2013.

Referências

ANP (AGÊNCIA NACIONAL DO PETRÓLEO, GÁS NATURAL E BIOCOMBUSTÍVEIS). Anuário estatístico brasileiro do petróleo, gás natural e biocombustíveis 2013. Rio de Janeiro: ANP, 2013. Anuário estatístico brasileiro do petróleo, gás natural e biocombustíveis 2016. Rio de Janeiro: ANP, 2018.

CONTRERAS, Edelmira d. C. A. Os desbravadores: a Petrobrás e a construção do Brasil industrial. Rio de Janeiro: Relume Dumará/ANPOCS, 1994.

COSTA, Pierre. A cidade do petróleo: uma geo-história do refino de petróleo no Brasil. Guarapuava: Unicentro, 2012.

GARCIA, Mônika C. P. Transformações na estrutura produtiva do Aglomerado Metropolitano de Curitiba. Dissertação (Mestrado em Geografia). PPGG, UNESP, Rio Claro, 2006.

EGLER, Cláudio A. G.; MATTOS, Margarida M. C. L. Multinacionais do setor petrolífero, geoeconomia e integração regional na América do Sul. In: MONIÉ, F.; BINSZTOK, J. (orgs.). Geografia e geopolítica do petróleo. Rio de Janeiro: Mauad X, 2012, p. 81-104.

FIEP (FEDERAÇÃO DAS INDÚSTRIAS DO PARANÁ). Cadastro das indústrias 2014. Curitiba: FIEP, 2015.

GAZETA DO POVO. Paraná tem oito cidades entre as 100 maiores economias do país. Gazeta do Povo, 14/12/2016. Disponível em http://www.gazetadopovo.com.br/economia/parana-tem-oitocidades-entre-as-100-maiores-economias-do-pais-dwvl2qiuyxtyjn7617v5x1j3b. Acesso em: 02 out. 2017.

LIMA, Miguel V. de. Petróleo e território no Brasil: a evolução do sistema de engenharia petrolífero e a configuração de seu circuito espacial produtivo. Tese (Doutorado em Geografia Humana). PPGH, USP, 2015.

LOURENÇO, Gilmar. M. A Petrobras e a industrialização do Paraná. Análise conjuntural, Curitiba, v. 25, n. 5-6, p. 18-20, mai./jun. 2003.

MORAES, Antônio C. R. Geografia histórica do Brasil: capitalismo, território e periferia. São Paulo: Annablume, 2011.

NEDER, Vinicius; NUNES, Fernanda. Transpetro cancela a construção de 17 navios. O Estadão de São Paulo. São Paulo, 27/10/2016. Disponível em http: http://economia.estadao.com.br/noticias/ geral,transpetro-cancela-a-construcao-de-17-navios,10000084919. Acesso em: 05 set. 2017. 
NEGRELLI, Márcia. J. O Papel do estado e das indústrias na produção do espaço e da qualidade de vida no Município de Araucária/PR. Dissertação (Mestrado em Geografia). PPGG, UFPR, Curitiba, 2004.

OLIVEIRA, Dennison de. Urbanização e industrialização no Paraná. Curitiba: SEED, 2001.

OLIVETTE, Priscila A.; COSTA, Pierre A. A vida política de Ney Braga: um estudo geohistórico. In: SEMANA DE GEOGRAFIA, 21, 2013, Guarapuava. Redes de geocolaboração: análise sócio-espacial, movimentos sociais, geotecnologias e ensino de geografia. Anais ... Guarapuava: UNICENTRO, 2013a, p. 1-6.

. Um estudo sobre a vida militar de Ney Aminthas de Barros Braga. In: Encontro Anual de Iniciação Científica (EAIC), 22, 2013, Foz do Iguaçu. Anais ... Cascavel: UNIOESTE, 2013b, v. 1, p. $1-4$.

PMA (PREFEITURA MUNICIPAL DE ARAUCÁRIA). Perfil do município de Araucária. Araucária: PMA, 2003.

SILVA, Madianita N. da. Indústria e produção do espaço urbano em Araucária. Dissertação (Mestrado em Geografia). PPGG, UFPR, Curitiba, 2006.

SKRZYPNIK, Lúcia de F. Educação e trabalho no município de Araucária: a questão da formação profissional de 1990 a 2006. Dissertação (Mestrado em Educação). PPGE, UFPR, Curitiba, 2009.

SOUZA, Marcelo L. de. Desenvolvimento urbano: a problemática renovação de um "conceito"problema. Território. Rio de Janeiro, n.5, p. 5-26, jul./dez. 1998.

TRANPETRO. Terminal aquaviário de Paranaguá - 30 anos. Rio de Janeiro: Transpetro, 2007.

. Transpetro: energia sem fronteiras. Rio de Janeiro: Transpetro, 2008.

. Transpetro. Disponível em http://www.transpetro.com.br/pt_br/home.html. Acesso em: 04 set. 2017.

UNIBIO. Projeto Ecológico Cinturão Verde. Disponível em http://unibiobrasil.com.br/index.php? option=com_content\&view=article\&id=49:projeto-ecologico-cinturao-verde-equipe-atualrodrigo-berte-coordenador-geral-do-projeto-rodrigo-fernando-schultz-administrador-luizgustavo-marzollo-especialista-em-ea-dauto-j-da-silveira-sociologo-daiane-mendes-de-larasecretaria-eds\&catid=3:novos-projetos\&Itemid=30. Acesso em: 20 set. 2017.

VELTZ, Pierre. Des lieux et des liens: politique du territoire à l'heure de la mondialisation. Paris: L1Aube, 204.

\section{NOTES}

1. Instituto Paranaense de Desenvolvimento Econômico e Social.

2. Para uma análise geohistórica mais completa ver Costa (2012 - capítulo II).

3. Popularmente conhecido como gás de cozinha.

4. Pesquisa intitulada "Análise geoeconômica de Araucária (PR): urbanização e industrialização a partir dos anos 1970", executada entre 2013 a 2016, com financiamento da Fundação Araucária (FA).

5. Os quais serão abordados posteriormente.

6. Centro Industrial de Araucária (ver mapa 2).

7. Ney Aminthas de Barros Braga foi governador do Paraná por duas vezes (1961-65 e 1979-1983). Ocupou também os cargos de Ministro da Agricultura (1965-66) e Ministro da Educação 
(1974-1978). Sobre mais detalhes da vida profissional desse importante político paranaense ver Olivette; Costa (2013a; 2013b).

8. Federação das Indústrias do Paraná.

9. Com capacidade inicial de processamento de $20 \mathrm{mil} \mathrm{m}^{3}$ de petróleo por dia.

10. Dados de 2017.

11. Sendo um dos principais municípios do Aglomerado Metropolitano de Curitiba (AMC).

12. Imposto sobre Circulação de Mercadorias e Serviços.

13. $\mathrm{R} \$ 65.153,00$.

14. Perdendo apenas para o município de Caraqueçaba com PIB per capita de $\mathrm{R} \$ 8.723,00$.

15. Instituto Brasileiro de Geografia e Estatística.

16. Observamos que não encontramos informações para esses dados no Censo Demográfico do IBGE 2010.

17. Derivados claros - designação genérica de alguns derivados de petróleo, entre os quais a gasolina, o querosene e o diesel. Possuem coloração clara, daí sua classificação. São líquidos e pouco viscosos. Derivados escuros - designação genérica de alguns derivados de petróleo, entre os quais o óleo combustível e o asfalto. Possuem coloração escura e alta viscosidade.

18. Éter metil terc-butílico, também conhecido como éter metil terciário butílico e MTBE (do inglês methyl tert-butyl ether), é um composto químico com fórmula molecular C5H12O. É utilizado como aditivo na gasolina sem chumbo para melhorar a combustão do motor.

19. Ressaltamos que a visita técnica ao Terminal, em 10/06/2015, não pode ser gravada. Ademais, não foram repassados materiais e informações sobre esse Terminal; dificultando, assim, uma análise qualitativa mais acurada.

20. Universidade Livre de Proteção à Biodiversidade.

\section{ABSTRACTS}

The main objective of this research is to reflect on the spatiality of petroleum refining activity in the territory of Paraná, from the installation of the Presidente Getúlio Vargas Refinery (REPAR) in the municipality of Araucária in 1977. For the construction of the same we make the reading and reflection of the bibliography raised. We also use a wide range of sources, where we highlight: newspapers, yearbooks, documents and interviews; technical visits to REPAR, IPARDES, in the Port of Paranaguá (PR), and at the Paranaguá Waterway Terminals (TEPAR) and São Francisco do Sul (TEFRAN). The socioeconomic transformations undergone by Araucaria reveal that the city lost the characteristic of only "rural-agrarian municipality"; experiencing accelerated processes of industrialization and urbanization. In the 1980s and 1990s the Araucária Petrochemical Complex began to be consolidated. However, despite all this economic growth, verified mainly since the 1970s, Araucária continues with serious social problems.

A pesquisa tem como intuito principal apontar uma reflexão acerca das espacialidades da atividade de refino de petróleo no território paranaense, a partir da instalação da Refinaria Presidente Getúlio Vargas (REPAR) no município de Araucária em 1977. Para a construção da mesma realizamos a leitura e reflexão da bibliografia levantada. Também utilizamos uma gama variada de fontes, onde destacamos: jornais, anuários, documentos e entrevista; visitas técnicas na REPAR, no IPARDES ${ }^{1}$, no Porto de Paranaguá (PR), e nos Terminais Aquaviários de Paranaguá (TEPAR) e São Francisco do Sul (TEFRAN). As transformações socioeconômicas sofridas por 
Araucária revelam que a cidade perdeu a característica de tão somente "município ruralagrário"; vivenciando processos acelerados de industrialização e urbanização. Nas décadas de 1980 e 90 começa a se consolidar o Polo Petroquímico de Araucária. Porém, apesar de todo este crescimento econômico, verificado principalmente a partir dos anos 1970, Araucária continua com sérios problemas sociais.

L'objectif principal de la recherche est de réfléchir à la spatialité de l'activité de raffinage du pétrole sur le territoire de Paraná, de l'installation de la raffinerie Presidente Getúlio Vargas (REPAR) dans la municipalité d'Araucária en 1977. Pour la construction de la même chose, nous faisons la lecture et la réflexion de la bibliographie évoquée. Nous utilisons également diverses sources, parmi lesquelles nous soulignons: journaux, annuaires, documents et interviews; Visites techniques au REPAR, à IPARDES, au port de Paranaguá (PR), aux terminaux de navigation de Paranaguá (TEPAR) et à São Francisco do Sul (TEFRAN). Les transformations socio-économiques subies par Araucaria révèlent que la ville a perdu la caractéristique de la seule "municipalité rurale-agraire"; expérimenter des processus d'industrialisation et d'urbanisation accélérés. Dans les années 1980 et 1990, le complexe pétrochimique Araucária a commencé à se consolider. Cependant, malgré toute cette croissance économique, constatée principalement depuis les années 1970, l'Araucária connaît encore de graves problèmes sociaux.

La investigación tiene como objetivo principal apuntar una reflexión acerca de las espacialidades de la actividad de refino de petróleo en el territorio paranaense, a partir de la instalación de la Refinería Presidente Getúlio Vargas (REPAR) en el municipio de Araucária en 1977. Para la construcción de la misma realizamos la lectura y reflexión de la bibliografía levantada. También utilizamos una gama variada de fuentes, donde destacamos: periódicos, anuarios, documentos y entrevista; en el IPARDES, en el Puerto de Paranaguá (PR), y en las Terminales Aquaviários de Paranaguá (TEPAR) y San Francisco del Sur (TEFRAN). Las transformaciones socioeconómicas sufridas por Araucária revelan que la ciudad perdió la característica de tan sólo "municipio ruralagrario"; vivenciando procesos acelerados de industrialización y urbanización. En las décadas de 1980 y 90 comienza a consolidarse el Polo Petroquímico de Araucaria. Sin embargo, a pesar de todo este crecimiento económico, verificado principalmente a partir de los años 1970, Araucaria continúa con serios problemas sociales.

\section{INDEX}

Mots-clés: industrie pétrolière, spatialité, logistique, Paraná.

Palavras-chave: Indústria Petrolífera, espacialidades, logística, Paraná.

Keywords: Petroleum Industry, Spatialities, Logistics, Paraná.

Palabras claves: Industria Petrolífera, espacialidades, logística, Paraná.

\section{AUTHORS}

\section{PIERRE COSTA}

Professor do Departamento de Geografia e Vice-Coordenador do PPGG da UNICENTRO (PR)

alvespierre75@hotmail.com

\section{LISANDRO PEZZI SCHMIDT}

Professor do Departamento de Geografia e do PPGG da UNICENTRO (PR)

lisandrops@hotmail.com 